\title{
Acute Febrile Encephalopathy: More Stringent Criteria Needed to Make a Correct Diagnosis
}

$$
\text { Sir, }
$$

Apropos of the published study ${ }^{1}$, the authors missed a few vital distinguishing features of 'acute encephalitis' from 'acute encephalopathy' that have significance in later characterization of the illness, and on occasion, spare clinicians to undertake many unwarranted exhaustive virological investigations. There is a tendency amongst clinicians and investigating agencies to jump to the conclusion that any illness with fever, altered sensorium, and seizures in young children is 'encephalitis' and all such episodes are due to viruses. This is not the case always. The differentiation of acute encephalitis cases from acute encephalopathy is at times quite difficult but certain distinguishing features are worth mentioning. Presence of low serum glucose, markedly raised liver enzymes, absence of pleocytosis on CSF examination, normal brain scans (except for brain edema), and no residual neurological deficit after recovery are few distinguishing features that should alert a treating clinician to explore a diagnosis other than acute viral encephalitis. ${ }^{2}$ Careful consideration of these finer points of differentiation between the two clinical entities is often necessary to prevent clinicians from pursuing an exhaustive search for a putative virus that never exists.

Categorization of acute febrile encephalopathy (AFE) cases under the tab of Reye syndrome (RS) deserves a serious reconsideration, chiefly due to vague nature of this syndrome. With the availability of sophisticated tests and much improved ability to diagnose many rare cases of inborn errors of metabolism, and other metabolic disorders with certain amount of precision, have further undermined the status of RS as a distinct entity. Reference to RS should be reserved for cases where presence of microvesicular steatosis is proved on liver histology, and history of aspirin consumption during a viral prodrome is well documented. For all other cases presenting as RS, 'Reyelike' illnesses would be a more appropriate term. However, in every case presenting as Reye-like encephalopathy, one should make sure every effort has been taken to rule out other causes, especially the metabolic and toxic causes.

Toxin-mediated encephalopathies should be given far greater consideration while dealing with a case of AFE, especially if the presentation is with features of 'acute encephalopathy' as described above. This group of illnesses is usually misdiagnosed, and often erroneously reported as 'acute encephalitis syndrome' or as 'Reye syndrome'. Recent experiences in India and in Bangladesh $^{3-5}$ have shown that environmental toxins, particularly plant derived toxins play a major role. Proper, detailed epidemiological investigations, usually difficult to undertake in sporadic cases, are must to zero in on a particular toxic agent, which further require sophisticated toxicological studies to conclusively prove its association.

\section{Dr. Vipin M. Vashishtha Consultant Pediatrician, Mangla Hospital, Shakti Chowk, Bijnor-246701 (UP) India E-mail:vmv@manglahospital.org}

\section{REFERENCES}

1. Karmarkar SA, Aneja S, Khare S, Saini A, Seth A, Chauhan BK. A Study of Acute Febrile Encephalopathy with Special Reference to Viral Etiology. Indian J Pediatr 2008; 75: 801-805.

2. John TJ. Outbreaks of killer brain disease in children: mystery or missed diagnosis? Indian Pediatr 2003; 40: 863-869.

3. Vashishtha VM, Kumar A, John TJ, Nayak NC. Cassia occidentalis poisoning-the probable cause of hepato-myoencephalopathy in children in western Uttar Pradesh. Indian J Med Res 2007; 125: 756-762.

4. Vashishtha VM, Kumar A, John TJ, Nayak NC. Cassia occidentalis Poisoning Causes Fatal Coma in Children in Western Uttar Pradesh. Indian Pediatr 2007; 44: 522-525.

5. Fatal outbreak from ingesting toxic plants in Sylhet District. ICDDR, B Health and Science Bulletin 2008; 6 : 12-17. Available at: http://www.icddrb.org/pub/publication.jsp?classification $\mathrm{ID}=56 \&$ pubID=9402 Accessed on September 21, 2008.

\section{Author's Reply}

I agree with Dr Vashishtha that one must be very careful in labelling a patient as " acute viral encephalitis". It is often a very difficult task in the acute setting with the limited laboratory and radiological diagnostic modalities that are available. The present study was a modest effort to tease out the various causes of so called acute encephalitis in a year which saw a nationwide japanese Encephilitis outbreak. Though CSF cell count, and chemistry largely aid in the differential diagnosis, the picture can some times be overlapping. I would think of cerebral malaria in a patient with the criteria that the author lays down for encephalopathy. It is interesting to note that tha author has linked plant toxins to encephalitic/encephalopathic presentation. We did not take this into consideration when we did the study on our patients.

Swati Arun Karmakar Deaprtment of Pediatrics, Lady Hardinge Medical College New Delhi-110001, India E-mail: swatikarmakar@gmail.com 